\title{
A Case of Sacroiliitis Developing After Löfgren's Syndrome
}

\author{
Löfgren Sendromu Sonrası Gelişen Bir Sakroileit Olgusu
}

\author{
Gülcan GÜRER, ${ }^{1}$ Ayşe İYIYAPICI UNUBOL, ${ }^{2}$ Gülnur TAŞÇI BOZBAŞ \\ ${ }^{1}$ Department of Physical Medicine and Rehabilitation, Van State Hospital, Van, Turkey; \\ ${ }^{2}$ Department of Physical Medicine and Rehabilitation, Kuşadast State Hospital, Aydin, Turkey; \\ ${ }^{3}$ Department of Physical Medicine and Rehabilitation, Special BSK Anka Hospital, Aydin, Turkey
}

Löfgren's syndrome is a form of acute-type sarcoidosis that is characterized by an association with erythema nodosum and bilateral hilar lymphadenopathy accompanied by arthritis or arthralgia. Sacroiliitis has been described in sarcoidosis but is thought to be very rare. In this article, a 38-year-old female with Löfgren's syndrome and sacroiliitis is described, and previously reported cases involving sarcoid sacroiliitis are briefly reviewed.

Key words: Löfgren's syndrome; sacroiliitis; sarcoidosis.

Sarcoidosis is a chronic, systemic disease of unknown origin and is characterized by the formation of noncaseating granulomas in the affected organs, mostly in the lungs. The illness can be self-limited or chronic with episodic recrudescences and remissions. Because the lungs and thoracic lymph nodes are mostly involved, most patients report acute or insidious respiratory problems accompanied by variable symptoms affecting the skin, eyes, or other organs. ${ }^{[1]}$

Different forms of arthritis in sarcoidosis are well known. Musculoskeletal involvement often manifests as inflammatory arthralgia (up to $40 \%$ of the cases)..$^{[2]}$ The joints most commonly affected are the knees, ankles, elbows, and wrists. However, radiologically identifiable abnormalities are rare. The combination of erythema nodosum, periarticular ankle
Löfgren sendromu, eritema nodozum ve iki taraflı hiler lenfadenopati, artrit veya artralji birlikteliği ile karakterize akut tip sarkoidoz formudur. Sakroileit sarkoidozda tanımlanmıştır, fakat oldukça nadir olduğu düşünülmektedir. Bu makalede, Löfgren sendromlu ve sakroileitli 38 yaşındaki bir kadın hasta sunulmakta ve daha önce bildirilmiş olan sarkoid sakroileitli olgular kısaca gözden geçirilmektedir.

Anahtar sözcükler: Löfgren sendromu; sakroileit; sarkoidoz.

inflammation, and mediastinal lymphadenopathy is designated as Löfgren's syndrome, which usually has a self-limiting course with spontaneous resolution. ${ }^{[3]}$

Sacroiliitis, a manifestation of sarcoid arthritis, has been described occasionally. ${ }^{[4]}$ In this article, a case of Löfgren's syndrome with sacroiliitis is presented.

\section{CASE REPORT}

A 38-year-old female was admitted to our clinic with a complaint of right ankle pain along with swelling and erythema nodules in her legs which had been occurring for five days. Although rest increased the pain, it also persisted while walking. Furthermore, she had been suffering from inflammatory hip pain for five years. In both her legs, there were subcutaneous, nodular, erythematous eruptions and painful swellings

\footnotetext{
Received: January 30, 2011 Accepted: April 10, 2011

Correspondence: Gülcan Gürer, M.D. Van Devlet Hastanesi Fiziksel Tıp ve Rehabilitasyon Kliniği, 65100 Van, Turkey.

Tel: +90 432 - 4441256 / 4227 e-mail: gurergulcan@yahoo.com.tr

Presented at the $8^{\text {th }}$ Turkish Rheumatology Symposium, December 3-6, 2009, Antalya, Turkey.

C2011 Turkish League Against Rheumatism. All rights reserved.
} 
which had begun three months prior to the current complaint of ankle swelling. Erythema nodosum (EN) was diagnosed, and another physician gave steroid treatment to the patient. The nodules were reduced with the treatment. In further questioning of the patient regarding an unrelated issue, it was revealed that she had had chills and shivering for the previous five days as well as a cough and loss of appetite for the last two months. There were no significant features in her personal and family histories.

The systemic examination of the patient was normal. In the muscle and skeleton system examination, the hip motion was normal and pain free, and the Flexion Abduction External Rotation (FABER) test was positive in the right hip. The patient had diffuse, round, subcutaneous, painful, stiff, red nodules in her lower extremities which were compatible with EN. The range of motion of the right ankle was restricted and painful. There was swelling and warmth on the right ankle and the dorsal side of the foot.

The laboratory testing results were as follows: rheumatoid factor (RF), $11 \mathrm{U} / \mathrm{ml}(0-20)$; erythrocyte sedimentation rate (ESR), $67 \mathrm{~mm} / \mathrm{h}(0-20)$; C-reactive protein (CRP), $85.43 \mathrm{mg} / \mathrm{dl} \mathrm{(0-5);} \mathrm{and} \mathrm{the} \mathrm{total}$ blood count, urea, creatinine, and electrolyte values were normal. The hepatitis, antinuclear antibody (ANA) along with the Salmonella and Brucella titers were all negative. The purified protein derivative (PPD) skin and pathergy tests were also negative. No findings were detected on the throat culture or in the direct fecal and parasite examinations. HLA-B27 was negative. A chest X-ray showed the hilar plenitude (figure 1). High resolution computed

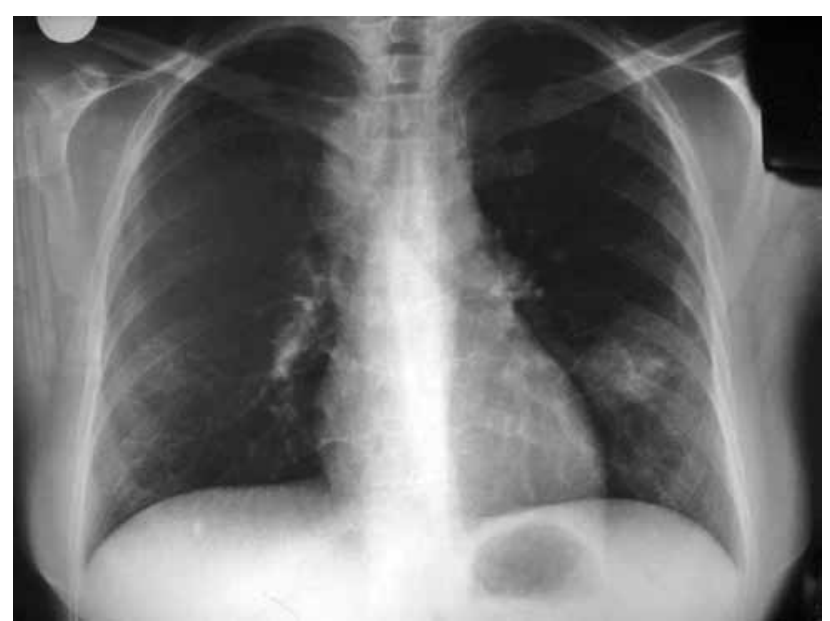

Figure 1. The posterior-anterior chest X-ray demonstrated the bilateral hilar lymphadenopathy. tomography (HRCT) revealed the bilateral hilar lymphadenopathy (LAP) and multiple mediastinal LAP along with several nodules adjacent to several irregular nodules (the largest was $2.5 \times 1.5 \mathrm{~cm}$ ) in both lungs, which was compatible with stage II sarcoidosis (figure 2). Using a gallium-67 whole body screening method, an activity enhancement in both the hilar and mediastinal regions was consistent with lymph node involvement. The diagnosis of sarcoidosis was confirmed by a bronchoscopic biopsy. A pelvis radiograph and sacroiliac magnetic resonance imaging (MRI) were performed, and the results were normal. The patient was diagnosed as having Löfgren's syndrome, which is a clinical subtype of acute sarcoidosis involving acute arthritis, LAP, and EN. Steroid treatment was administered, and recovery was observed on the arthritis of the right ankle and EN after two weeks. On follow-up, the clinical and laboratory findings (ESR, $35 \mathrm{~mm} / \mathrm{h}$; CRP, $7.89 \mathrm{mg} / \mathrm{dl}$ ) had improved dramatically. During the clinic management of the patient at three months, the patient complained about hip pain, so a radiograph of the sacroiliac joint was performed again. Sclerosis was shown in the inferior regions of both sacroiliac joints on the sacroiliac X-ray (figure 3), and right sacroiliitis was found on the MRI of the sacroiliac joints (figure 4). The complaints of the patient were address by administering nonsteroidal antiinflammatory drugs (NSAIDs), and the patient continued to be followed up.

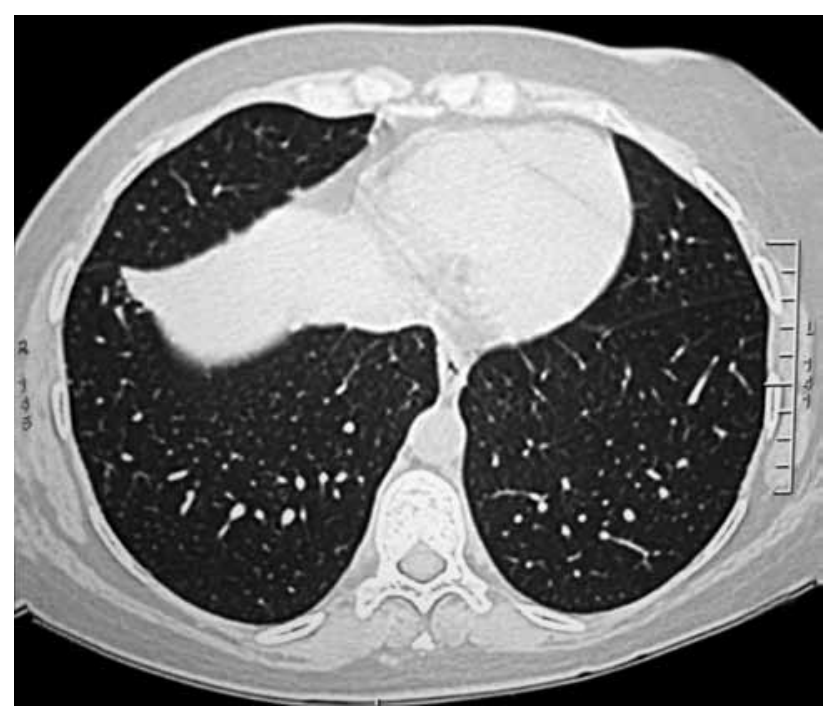

Figure 2. High resolution computer tomography revealed the bilateral hilar lymphadenopathy and multiple mediastinal lymphadenopathy along with several nodules adjacent to several irregular nodules in both lungs. This was compatible with stage II sarcoidosis. 


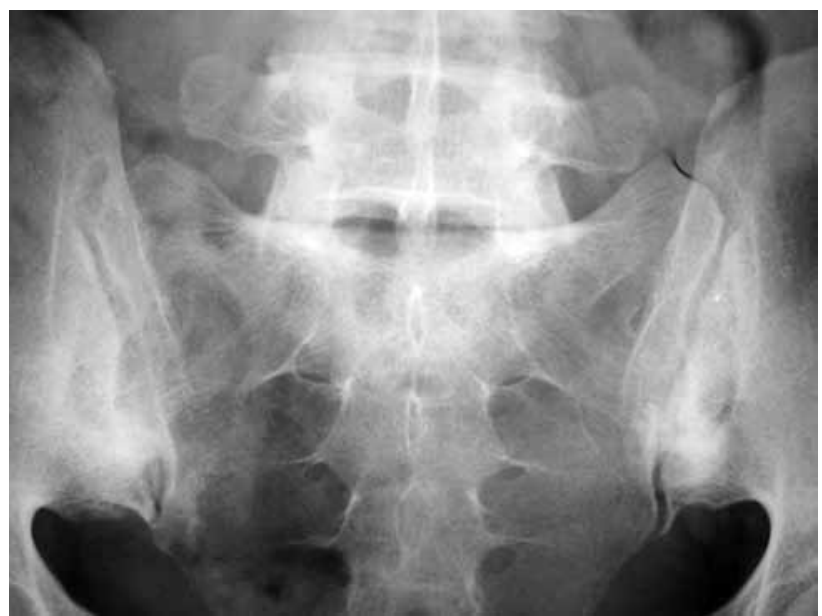

Figure 3. Sacroiliac X-ray showed sclerosis in the inferior regions of both sacroiliac joints.

\section{DISCUSSION}

Sarcoidosis is a chronic, systemic disease of unknown origin and is characterized by the formation of noncaseating granulomas in the affected organs, most commonly the lungs. ${ }^{[5]}$ Joint involvement in sarcoidosis is usually manifested as acute symmetric polyarthritis without joint destruction that affects the ankles, knees, and wrists. This pattern is a component of Löfgren's syndrome. Löfgren's syndrome is regarded as a self-limiting disease that is generally resolved within three months. Joint destruction can occur in chronic forms. Management usually relies on nonsteroidal anti-inflammatory agents or low-dose prednisone, and the course is usually benign. In the few refractory cases, methotrexate, hydroxychloroquine, or even cyclosporine can be used ${ }^{[6]}$ Herein, we have presented a patient with sacroiliitis that began as Löfgren's syndrome. The patient also had arthritis involving the right ankle, but the arthritis complaints were reduced with steroid treatment.

In 1953, Lofgren and Lundback ${ }^{[7]}$ characterized 212 adult patients on bilateral hilar LAP who were practically regarded as having sarcoidosis based on no active evidence of tuberculosis and on histopathologic evidence of sarcoidosis obtained through contemporary biopsy techniques in $47 \%$ of the cases. Lofgren ${ }^{[8]}$ demonstrated that EN was present at the onset of disease in 113 cases in which articular symptoms were common (101 cases, 89\%). There was either pain only in the joints $(20 \%)$, or the pain was accompanied by swelling (69\%). ${ }^{[7,8]}$ The acute form of sarcoidosis with EN, bilateral hilar LAP, and arthritis or arthralgia is particularly frequent among young women from

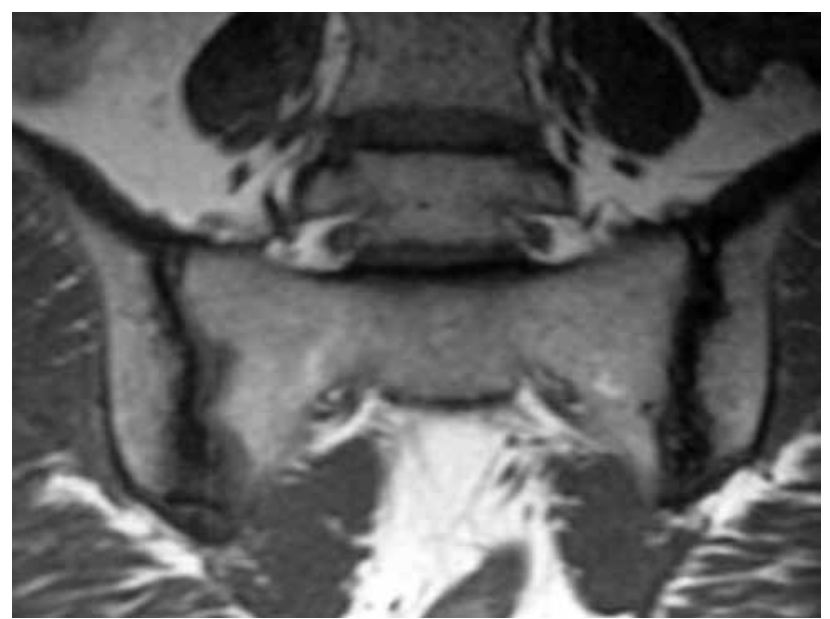

Figure 4. Magnetic resonance imaging of the sacroiliac joints demonstrated the right sacroiliitis.

Nordic countries and Ireland; it is uncommon among black people. ${ }^{[3,7-9]}$ However, more patients with this syndrome might go unnoticed among the Japanese population. Interestingly, arthralgia is an infrequent (only 1.6\%) symptom of sarcoidosis among Japanese patients, but it is common (25-50\%) among white people. ${ }^{[10.11]}$ Okumuş et al. ${ }^{[12]}$ investigated the extrapulmonary involvement in Turkish patients with sarcoidosis. One hundred and nineteen out of 293 patients ( 83 females, 36 males; mean age $45 \pm 12$ years) had extrapulmonary involvement in this study (40.6\%). Skin and peripheral lymph node involvement were the most common sites of extrapulmonary involvement, and ocular involvement was more common in those under the age of 40 in patients with sarcoidosis in a Turkish population. Extrapulmonary symptoms were present in $181(61.8 \%)$ patients, and skin lesions, arthralgia, and back pain were the most common of these $(33.4 \%, 20.8 \%$ and $16.4 \%$, respectively).

Arthritis of the sacroiliac joints (sacroiliitis) has been described in patients with sarcoidosis; however, it is thought to be rare.$^{[5]}$ In 1951, Verstraeten and Bekaert ${ }^{[6]}$ reported the first case of a patient with both sacroiliitis and sarcoidosis. In the case reported by Griep et al., ${ }^{[13]}$ sacroiliitis was unilateral. Pulmonary tuberculosis had been diagnosed before the occurrence of sacroiliitis and was treated by antituberculous triple therapy in these cases. A biopsy revealed noncaseating epithelioid cell granulomas without microscopic or culture evidence of a mycobacterial infection. The sacroiliitis dramatically regressed with steroid therapy, although antituberculous therapy was discontinued. Thus, the diagnosis of sarcoid sacroiliitis was made. Kötter et al. ${ }^{[14]}$ reported two cases with bilateral sacroiliitis in 
sarcoidosis, and tuberculosis was excluded by negative tuberculin skin tests, bronchoalveolar lavage, and transbronchial biopsy. We have reported a case involving a 38-year-old woman with sarcoidosis and sacroiliitis. Tuberculosis was eliminated by negative tuberculin skin tests, bronchoalveolar lavage, and a scalene lymph node biopsy.

HLA-B8 and HLA-DR3 have been associated with the acute onset of sarcoidosis with arthritis. ${ }^{[15,16]}$ On the other hand, it is known that there is a clear association between ankylosing spondylitis and HLA-B27. ${ }^{[17]}$ In the study of Stucki et al., ${ }^{[18]}$ describing a patient with sarcoid sacroiliitis, HLA-B27 as well as HLA-B8 and HLA-DR3 were interestingly found to be positive. In contrast, HLA-B27 was negative in our patient.

The prevalence of spondyloarthropathy in the normal population has been estimated to be $1.9 \%{ }^{[7]}$ In the sarcoid population studied by Erb et al., ${ }^{[5]}$ the prevalence of spondyloarthropathy was $6.6 \%$ suggesting a possible association between these two conditions.

There exists a relationship between granulomatous diseases, especially sarcoidosis, and Whipple's disease as a form of seronegative enteritis-associated arthritis. ${ }^{[19]}$ Sacroiliitis has been described in Whipple's disease and tuberculosis. ${ }^{[13]}$

In conclusion, sacroiliitis should be suspected in patients with sarcoidosis who have persistent hip pain, and the necessary investigations should be performed for sacroiliitis.

\section{Declaration of conflicting interests}

The authors declared no conflicts of interest with respect to the authorship and/or publication of this article.

\section{Funding}

The authors received no financial support for the research and/or authorship of this article.

\section{REFERENCES}

1. Newman LS, Rose CS, Maier LA. Sarcoidosis. N Engl J Med 1997;336:1224-34.

2. Statement on sarcoidosis. Joint Statement of the American Thoracic Society (ATS), the European Respiratory Society (ERS) and the World Association of Sarcoidosis and Other Granulomatous Disorders (WASOG) adopted by the ATS Board of Directors and by the ERS Executive Committee, February 1999. Am J Respir Crit Care Med 1999;160:736-55.
3. Mañá J, Gómez-Vaquero C, Montero A, Salazar A, Marcoval J, Valverde J, et al. Löfgren's syndrome revisited: a study of 186 patients. Am J Med 1999;107:240-5.

4. Job-Deslandre C, Feldmann JL, Prieur AM, Menkes CJ. Chronic articular manifestations of sarcoidosis. Apropos of 7 cases. Ann Med Interne (Paris) 1984;135:139-43. [Abstract]

5. Erb N, Cushley MJ, Kassimos DG, Shave RM, Kitas GD. An assessment of back pain and the prevalence of sacroiliitis in sarcoidosis. Chest 2005;127:192-6.

6. Verstraeten JM, Bekaert J. Association of ankylosing spondylitis and sarcoidosis. Acta Tuberc Belg 1951;42:149-51.

7. Lofgren $S$, Lundback $H$. The bilateral hilar lymphoma syndrome; a study of the relation to tuberculosis and sarcoidosis in 212 cases. Acta Med Scand 1952;142:265-73.

8. Lofgren S. Primary pulmonary sarcoidosis. I. Early signs and symptoms. Acta Med Scand 1953;145:424-31.

9. Costabel U, Hunninghake GW. ATS/ERS/WASOG statement on sarcoidosis. Sarcoidosis Statement Committee. American Thoracic Society. European Respiratory Society. World Association for Sarcoidosis and Other Granulomatous Disorders. Eur Respir J 1999;14:735-7.

10. Ando M. Recent epidemiological features of sarcoidosis in Japan. Nippon Rinsho 1994;52:1433-7. [Abstract]

11. Pietinalho A, Ohmichi $M$, Hiraga $Y$, Löfroos $A B$, Selroos O. The mode of presentation of sarcoidosis in Finland and Hokkaido, Japan. A comparative analysis of 571 Finnish and 686 Japanese patients. Sarcoidosis Vasc Diffuse Lung Dis 1996;13:159-66.

12. Okumus G, Musellim B, Cetinkaya E, Turker H, Uzaslan E, Yenturk E, et al. Extrapulmonary involvement in patients with sarcoidosis in Turkey. Respirology 2011;16:446-50.

13. Griep EN, van Spiegel PI, van Soesbergen RM. Sarcoidosis accompanied by pulmonary tuberculosis and complicated by sacroiliitis. Arthritis Rheum 1993;36:716-21.

14. Kötter I, Dürk H, Saal JG. Sacroiliitis in sarcoidosis: case reports and review of the literature. Clin Rheumatol 1995; 14:695-700.

15. Hedfors E, Lindström F. HLA-B8/DR3 in sarcoidosis. Correlation to acute onset disease with arthritis. Tissue Antigens 1983;22:200-3.

16. Kremer JM. Histologic findings in siblings with acute sarcoid arthritis: association with the B8,DR3 phenotype. J Rheumatol 1986;13:593-7.

17. Kim TH, Uhm WS, Inman RD. Pathogenesis of ankylosing spondylitis and reactive arthritis. Curr Opin Rheumatol 2005;17:400-5.

18. Stucki G, von Felten A, Speich R, Michel BA. Ankylosing spondylitis and sarcoidosis-coincidence or association? Case report and review of the literature. Clin Rheumatol 1992;11:436-9.

19. Rouillon A, Menkes CJ, Gerster JC, Perez-Sawka I, Forest M. Sarcoid-like forms of Whipple's disease. Report of 2 cases. J Rheumatol 1993;20:1070-2. 